Int. J. Electrochem. Sci., 14 (2019) $11138-11151$

\title{
Surface Characteristics and Electrochemical Performance of Activated Carbons from Schinus molle Stones Prepared by Hydrothermal Carbonization and KOH Activation
}

\author{
Carlos Moreno-Castilla*, Helena García-Rosero, Francisco Carrasco-Marín. \\ Departamento de Química Inorgánica, Facultad de Ciencias, Universidad de Granada, 18071 Granada, \\ Spain. \\ *E-mail: cmoreno@ugr.es
}

doi: $10.20964 / 2019.12 .83$

Received: 20 February 2019 / Accepted: 30 March 2019 / Published: 29 October 2019

Schinus molle (SM) stones contain ca. $47 \% \mathrm{C}$ and $1 \% \mathrm{~N}$ and are therefore a potential raw material for the preparation of activated carbons (ACs) with $\mathrm{N}$ functionalities. In this study, we investigated the usefulness of SM stones to prepare ACs by hydrothermal carbonization (HTC) followed by $\mathrm{KOH}$ activation. For comparison purposes, ACs were also prepared by direct $\mathrm{KOH}$ activation of pristine SM stones. The objective was to study the effects of each preparation method on the physico-chemical surface and electrochemical performance of the ACs obtained. Ash content was lower and N content higher in ACs produced by HTC-KOH activation (HSM series) versus direct $\mathrm{KOH}$ activation (SM series). All ACs, except the most highly activated sample from the HSM series, had narrow micropores or constricted micropore entrances. The highest surface area and mesopore volume obtained were 1464 $\mathrm{m}^{2} \mathrm{~g}^{-1}$ and $0.29 \mathrm{~cm}^{3} \mathrm{~g}^{-1}$, respectively. Examination of AC porosity and surface area indicated that SM stones were more reactive to $\mathrm{KOH}$ activation after HTC. AC HSM200-2 had the largest capacitance, $235 \mathrm{~F} \mathrm{~g} \mathrm{~g}^{-1}$ at $0.5 \mathrm{~A} \mathrm{~g}^{-1}$, and the highest energy density, $7.83 \mathrm{Wh} \mathrm{kg}^{-1}$, at a power density of $400 \mathrm{~W} \mathrm{~kg}^{-1}$. The electrochemical performance of this sample was comparable to that recently reported for a wide variety of biomass-based ACs.

Keywords: Activated carbons; Schinus molle stones; Hydrothermal carbonization; Surface characteristics; Electrochemical performance.

\section{FULL TEXT}

(C) 2019 The Authors. Published by ESG (www.electrochemsci.org). This article is an open access article distributed under the terms and conditions of the Creative Commons Attribution license (http://creativecommons.org/licenses/by/4.0/). 